
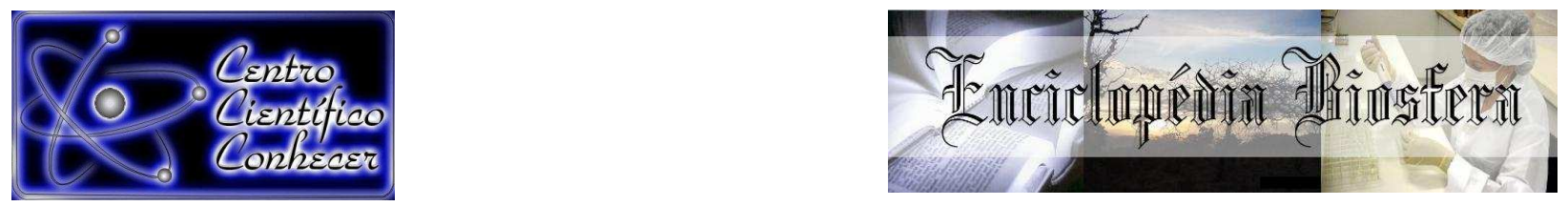

\title{
SISTEMATIZAÇÃO DA EQUAÇÃO UNIVERSAL DE PERDA DE SOLO (EUPS) EM SISTEMA DE INFORMAÇÃO GEOGRÁFICA (SIG) NA ESTIMATIVA DA EROSÃO NO MUNICÍPIO DE FRANCISCO BELTRÃO - PARANÁ
}

Juliane Mônica Ruthes ${ }^{(1)}$, Júlio Caetano Tomazoni ${ }^{(2)}$ e Tayoná Cristina Gomes ${ }^{(3)}$

${ }^{(1)}$ Mestranda do Programa de Pós Graduação em Engenharia Agrícola da Universidade Estadual do Oeste do Paraná (UNIOESTE) - Cascavel - PR, Brasil (julianeruthes@yahoo.com.br)

(2) Professor Doutor do Departamento de Engenharia Ambiental da Universidade

Tecnológica Federal do Paraná (UTFPR) - campus Francisco Beltrão

${ }^{(3)}$ Mestranda do Programa de Pós Graduação em Ciência e Tecnologia Ambiental da

Universidade Federal da Fronteira Sul (UFFS) - Campus Erechim

Recebido em: 08/04/2016 - Aprovado em: 30/05/2016 - Publicado em: 20/06/2016 DOI: 10.18677/Enciclopedia_Biosfera_2016_107

Com o objetivo de estimar a perda de solo por erosão laminar no município de Francisco Beltrão - Pr, foi sistematizada a equação universal de perda de solo (EUPS) em Sistema de Informação Geográfica, aplicando-se a álgebra de mapas. Considerando-se as características pluviométricas, topográficas, tipos de solo e uso da terra do município, foram definidos individualmente os parâmetros que compõe a equação universal de perda de solo e posteriormente, integralizou-se os fatores e obtiveram-se os valores de perda média anual de solo para o município de Francisco Beltrão. No geral, as perdas de solos foram inferiores a 10 t.ha $^{-1}$.ano ${ }^{-1}$, abrangendo cerca de $72 \%$ da área total do município, entretanto, valores altos de perdas de solo foram encontrados em aproximadamente $20 \%$ da área, acima de 50 t.ha ${ }^{-1}$.ano ${ }^{-1}$. A integração dos dados indicou eficiência na identificação da perda de solo por erosão laminar e permitiu a análise das potencialidades do município, referente aos usos do solo atuais, dispondo de informações importantes para o controle de práticas que intensifiquem o processo erosivo em Francisco Beltrão.

PALAVRAS-CHAVE: álgebra de mapas, perda de solo, processo erosivo.

\section{SYSTEMATIZATION OF UNIVERSAL SOIL LOSS EQUATION (USLE) IN GEOGRAPHIC INFORMATION SYSTEM (GIS) IN EROSION ESTIMATION IN THE MUNICIPALITY OF FRANCISCO BELTRÃO - PARANA}

\begin{abstract}
With the objective to estimate soil loss by laminate erosion in Francisco Beltrão country, State of Parana, was systematized the universal soil loss equation (USLE) in Geographic Information System, applying the map algebra. Considering the pluviometric characteristics, topographic particulars, soil types and land use in the municipality, were individually defined parameters that compose the universal soil loss equation and subsequently paid in the factors and obtained the values of mean annual soil loss for the Francisco Beltrão city. Overall, the loss of soil were less than 10 t.ha $^{-1}$.year ${ }^{-1}$, including about $72 \%$ of the total area of the municipality, however,
\end{abstract}


high values of soil loss were found in approximately $20 \%$ of the area, above 50 t.ha ${ }^{1}$.year ${ }^{-1}$. The integration of the data indicated efficiency in the identification of soil loss by laminate erosion and permitted the analysis of the potential of the municipality, referring to present uses of soil, offering important information to control practices that intensify the erosive process in Francisco Beltrão.

KEYWORDS: erosive process, map algebra, soil loss.

\section{INTRODUÇÃO}

A intensificada erosão do solo constitui em um dos principais incômodos ambientais ocasionados por atividades agrícolas. A erosão hídrica apresenta grande relevância em regiões com clima tropical e colabora na deterioração dos solos, uma vez que acarreta na perda da sua camada mais fértil (BERTONI \& LOMBARDI NETO, 2008), podendo causar assoreamento dos corpos d'água, por meio do transporte de partículas pelas encostas. O reconhecimento de áreas com solos vulneráveis a erosão hídrica apresenta-se relevante, especialmente, em superfícies onde não ocorrem planejamentos de conservação do solo, nem o estudo dos fatores e da evolução de processos que permitem o agravamento destes eventos (ARRAES et al., 2010).

NÓBREGA \& COSTA (2008) dizem que para o planejamento e controle dos processos erosivos, são aplicados métodos matemáticos na previsão de diferentes cenários, de maneira rápida e com gastos reduzidos. Os modelos de predição de perda de solo por erosão hídrica, quando integrados às técnicas de geoprocessamento, permitem prever as perdas de solo e definir técnicas de controle e ações que facilitem o planejamento ambiental.

Entre as metodologias empregadas na predição das supressões de solo submetido a diferentes condições de uso e práticas conservacionistas, evidencia-se a Equação Universal de Perda de Solo (EUPS), sendo passível de ser espacializada em sistema de informação geográfica, permitindo a avaliação do decréscimo de solo por erosão laminar. Inúmeras pesquisas têm sido desenvolvidas devido à necessidade de se estabelecer uma metodologia eficaz na avaliação precisa dos fatores que dão origem a erosão e estimar as consequentes perdas de solo. Com isso, diversos trabalhos têm adotado o uso dos sistemas de informação geográfica para a determinação dos fatores da EUPS (MATI et al, 2000; GUIMARÃES et al., 2011; DEVATHA et al., 2015; GANASRI \& RAMESH, 2015; SANTOS et al., 2015).

A EUPS é composta pelos principais parâmetros atuantes na erosão hídrica, e demostra a ação desses fatores no processo erosivo, sendo: a erosividade da chuva, a erodibilidade do solo, a topografia do terreno e o manejo do solo e as práticas de conservação oferecidas (BERTONI \& LOMBARDI NETO, 2008).

O levantamento dos dados pluviométricos locais permite definir o potencial da chuva em causar erosão, além disso, as características edáficas de cada solo revelam a susceptibilidade à erosão provocada pela chuva, logo, é indispensável a estimativa dessas propriedades para o entendimento do processo erosivo (BERTONI \& LOMBARDI NETO, 2008). Os parâmetros topográficos devem ser levados em conta ao se determinar a erosão laminar, pois estas características afetam drasticamente a perda de solos, aumentando a velocidade do transporte de sedimentos quando apresentam maiores comprimentos das vertentes ou elevado grau de declividade, principalmente se este solo encontra-se desprotegido (CARVALHO, 2008).

As práticas de uso, manejo e conservação do solo comprometem a infiltração da água no solo, danificam a estrutura, promovem a perda de sedimentos, 
confirmando a influência no processo erosivo (NÓBREGA \& COSTA, 2008). O objetivo deste trabalho foi quantificar a erosão laminar do município de Francisco Beltrão, por meio da sistematização da Equação Universal de Perda de Solos em Sistema de Informação Geográfica a partir da aplicação das técnicas de álgebra de mapas.

\section{MATERIAL E MÉTODOS}

A área de estudo compreende o município de Francisco Beltrão - PR, no sudoeste do estado do Paraná, apresentando coordenadas geográficas: a oeste

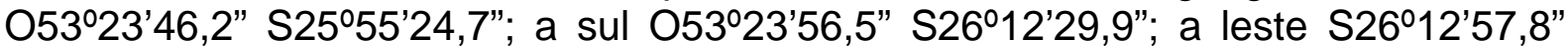

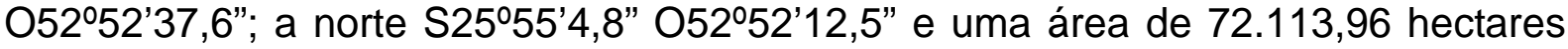
(Figura 1).

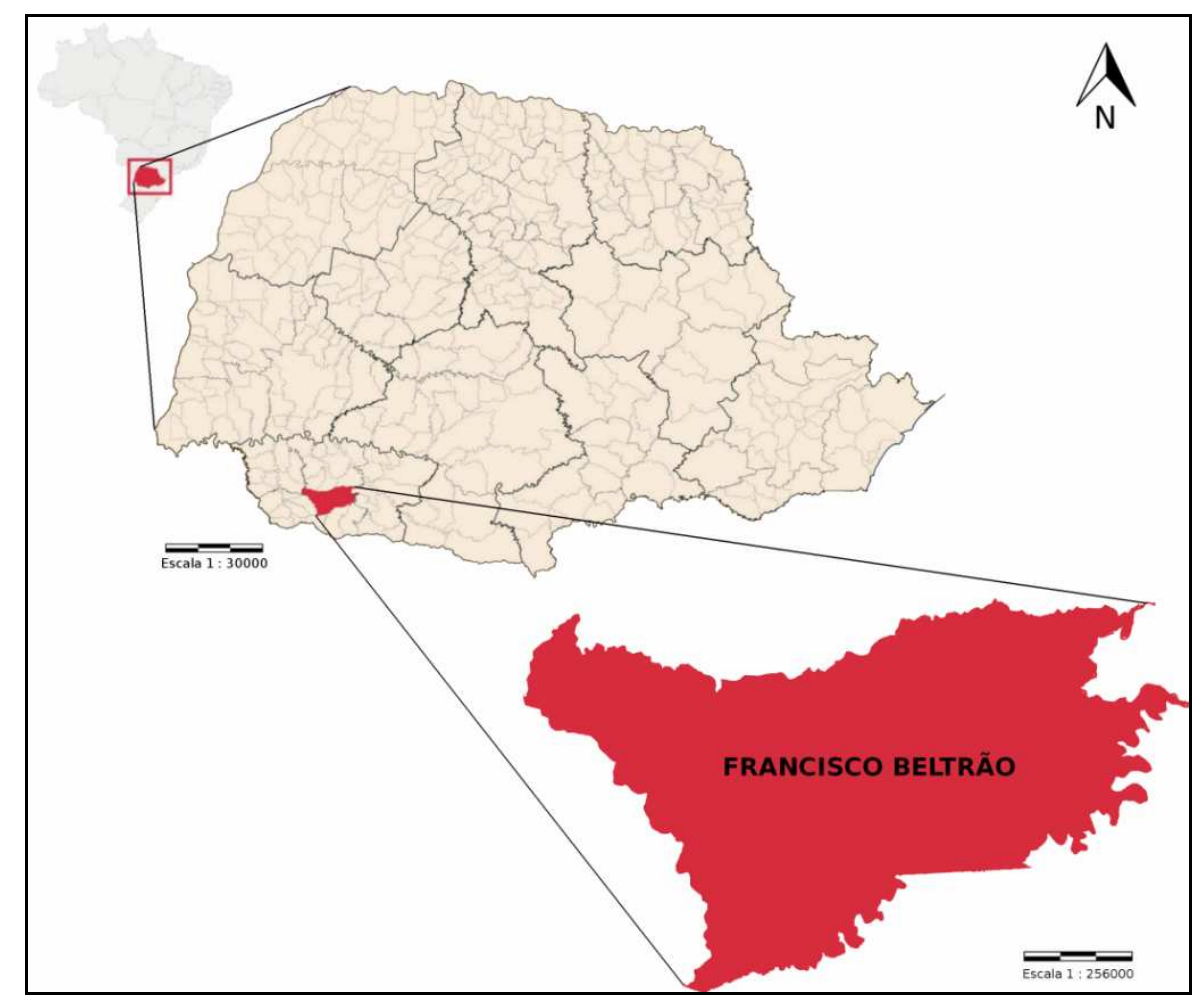

FIGURA 1. Localização do município de Francisco Beltrão no sudoeste do estado do Paraná.

\section{Equação Universal de Perda de Solo (EUPS)}

Para a quantificação da perda de solo por erosão laminar, utilizou-se o modelo matemático proposto por WISCHMEIER \& SMITH (1978) (Equação 1), o qual expressa o comportamento dos fatores que influenciam diretamente na erosão hídrica (NEVES et al., 2011).

$$
A=R * K * L S * C P
$$

Onde:

$A=$ perda média anual de solo em tonelada por ha;

$\mathrm{R}=$ erosividade das chuvas em $\mathrm{MJ} / \mathrm{ha}-\mathrm{mm} / \mathrm{a}$;

$\mathrm{K}=$ erodibilidade do solo em $\mathrm{t}$ ha $\mathrm{h} / \mathrm{ha} \mathrm{MJ} \mathrm{mm} / \mathrm{a}$; 
LS= fator declividade e comprimento de rampa (adimensional);

$\mathrm{C}=$ uso e manejo do solo (adimensional);

$\mathrm{P}=$ práticas conservacionistas (adimensional).

\section{Integração da EUPS às técnicas de geoprocessamento}

Para assimilar a EUPS ao geoprocessamento fez-se o uso do sistema de informação geográfica SRING (Sistema de Processamento de Informações Georreferenciadas), versão 5.2.6 (INPE, 2014). Na determinação dos fatores da equação universal de perda de solo utilizou-se o comando LEGAL (Linguagem Espacial para Geoprocessamento Algébrico) inserido ao software Spring, que é composto em três partes: declarações, onde se declaram variáveis associando às categorias já existentes; instanciações, onde dados são recuperados ou novos são criados; e operações, onde são realizadas as operações de álgebra de mapas. Ainda no Spring, com a ferramenta Scarta, foram gerados mapas vetoriais para os resultados obtidos.

\section{Fator Erosividade (R)}

O fator erosividade da chuva $(\mathrm{R})$ foi obtido a partir da digitalização de isoietas no software Spring, realizadas com auxilio da carta de Precipitação Anual do estado do Paraná, escala 1:2.000.000, desenvolvida pela SUDERHSA (1998). Criou-se um modelo numérico do terreno, gerando-se uma grade retangular com os valores de precipitação anual em $\mathrm{mm}$ de todo o município. Utilizando-se da ferramenta LEGAL disponível no Spring, desenvolveu-se um programa que associou a grade retangular de precipitação à equação de erosividade da chuva (Equação 2), resultando em valores do índice de erosividade do município.

$$
R=\left(67,355 *\left(\frac{p^{2}}{p}\right)^{0,85}\right) * 12
$$

Onde $\mathrm{R}$ é o índice de erosividade das chuvas (MJ.mm/ha.a); $\mathrm{p}$ é a precipitação média mensal $(\mathrm{mm} / \mathrm{mês})$ e $P$ é a precipitação média anual $(\mathrm{mm} / \mathrm{a})$.

\section{Fator Erodibilidade (K)}

Para obter o fator K, coletaram-se 52 amostras de solo no horizonte A e B ao longo do município, e posteriormente, desenvolveu-se análise granulométrica das amostras para a obtenção dos teores de silte, argila e areia, pelo método da pipeta (EMBRAPA, 1997). Para a quantificação da matéria orgânica usou-se a metodologia da digestão úmida. Partindo dos resultados das análises, utilizou-se a equação desenvolvida por DENARDIN (1990) para solos do Brasil e EUA (Equação 3) em software Excel e encontraram-se valores do fator erodibilidade.

$$
K=(0,00000748 * M)+(0,00448059 * P)-(0,0631175 * D M P)+(0,01039567 * R)
$$

Onde:

$\mathrm{K}=$ erodibilidade expressa em tha ${ }^{-1} \cdot$ h. $\mathrm{mm}^{-1} \cdot$ ha. $\mathrm{MJ}^{-1}$;

$M=(\text { Areia Fina }(\%)+\text { Silte }(\%))^{*}($ Areia Fina $(\%)+$ Silte $(\%)+$ Areia Grossa $(\%))$; 
$\mathrm{P}=$ permeabilidade do solo (Codificada): 1 = muito baixa, 2 = baixa, 3 = baixa

a moderada, 4 = moderada, $5=$ moderada a rápida, 6 = rápida;

$\mathrm{DMP}=$ Diâmetro médio das partículas dado por: $\left[\left(0,65^{\star}\right.\right.$ Areia Grossa(\%) $)+\left(0,15^{\star}\right.$ Areia Fina(\%)) $+\left(0,0117^{\star}\right.$ Silte(\%) $)+\left(0,00024^{*}\right.$ Argila(\%) $\left.)\right] / 100$;

$\mathrm{R}=$ Nova Areia dado por: [Areia Grossa(\%)*(Matéria Orgânica(\%)/100)].

No Spring, foram classificados os solos da Bacia, a partir do mapa de solos do estado do Paraná, desenvolvido pela EMBRAPA (2008). Por meio do programa LEGAL, atribuíram-se os valores encontrados de $\mathrm{K}$ para os solos classificados do município, resultando em uma grade retangular com os valores do fator erodibilidade de todo o município de Francisco Beltrão.

\section{Fator Topográfico (LS)}

Para a obtenção do fator topográfico (LS), iniciou-se com a edição da rede hidrográfica e das curvas de nível do município de Francisco Beltrão, no Spring, onde foi gerada uma grade retangular com os valores hipsométricos do município. Posteriormente, criou-se uma matriz da declividade do município de Francisco Beltrão, em porcentagem.

Com a edição dos divisores de água, pode-se associar à hidrografia do município e produzir uma grade retangular com os comprimentos de rampa do município. Pela linguagem LEGAL, associaram-se a declividade do município com os comprimentos de rampa, obtendo-se uma grade retangular com os valores do fator LS, por meio da equação do fator topográfico (Equação 4):

$$
L S=0,00984 *\left(L^{0,63}\right) *\left(S^{1,18}\right)
$$

Onde: LS é o fator topográfico (adimensional); L é o comprimento de rampa em $\mathrm{m}$; $\mathrm{S}$ é a declividade em \%.

\section{Fator Uso e Manejo do Solo e Práticas Conservacionistas (CP)}

Para determinar o fator CP, classificou-se o uso do solo do município de Francisco Beltrão, a partir das imagens do satélite Landsat 8 de 27 de julho de 2013, bandas 3, 4, 5 e 8, correspondentes ao azul, vermelho, verde e pancromático, respectivamente (INPE, 2013). A classificação da imagem deu-se pelo método de regiões, utilizando-se o classificador Batthacharya, com limiar de aceitação de 99\%. Utilizando a álgebra de mapas, por meio da linguagem LEGAL, aplicaram-se valores ao fator $\mathrm{C}$ (uso e manejo do solo) e fator $\mathrm{P}$ (práticas conservacionistas) obtidos em bibliografias (Tabela 1) aos diferentes usos do solo do município, gerando uma grade e uma imagem do modelo numérico do terreno.

TABELA 1. Valores de $C$ e $P$ para os tipos de cobertura no Município de Francisco Beltrão, Pr.

\begin{tabular}{ccc}
\hline Tipo de cobertura do solo & Fator C & Fator P \\
\hline Solo exposto & 1,000 & 0,50 \\
Lavouras & 0,253 & 0,50 \\
Pastagens & 0,015 & 0,30 \\
Vegetação & 0,001 & 0,01 \\
Urbanização & 0,007 & 0,04 \\
\hline
\end{tabular}

Fonte: Adaptado de BERTONI \& LOMBARDI NETO (2008). 


\section{Perda de Solo (A)}

A determinação da perda de solo do município de Francisco Beltrão consistiu no desenvolvimento de um programa LEGAL, onde utilizou-se como operação algébrica a Equação Universal da Perda de Solo (Equação 1), associada às grades do modelo numérico dos fatores componentes do modelo EUPS, resultando nos valores da perda média anual de solo no município de Francisco Beltrão.

\section{RESULTADOS E DISCUSSÃO}

\section{Fator Erosividade (R)}

De acordo com a carta de precipitação anual da SUDERHSA (1998), os valores médios de precipitação para o município de Francisco Beltrão variam entre 1750 a 2150 mm/ano. Foram encontrados valores de erosividade entre 6650 e 7850 MJ.ha ${ }^{-1} \cdot \mathrm{mm} \cdot \mathrm{h}^{-1} \cdot \mathrm{ano}^{-1}$ (Figura 2).

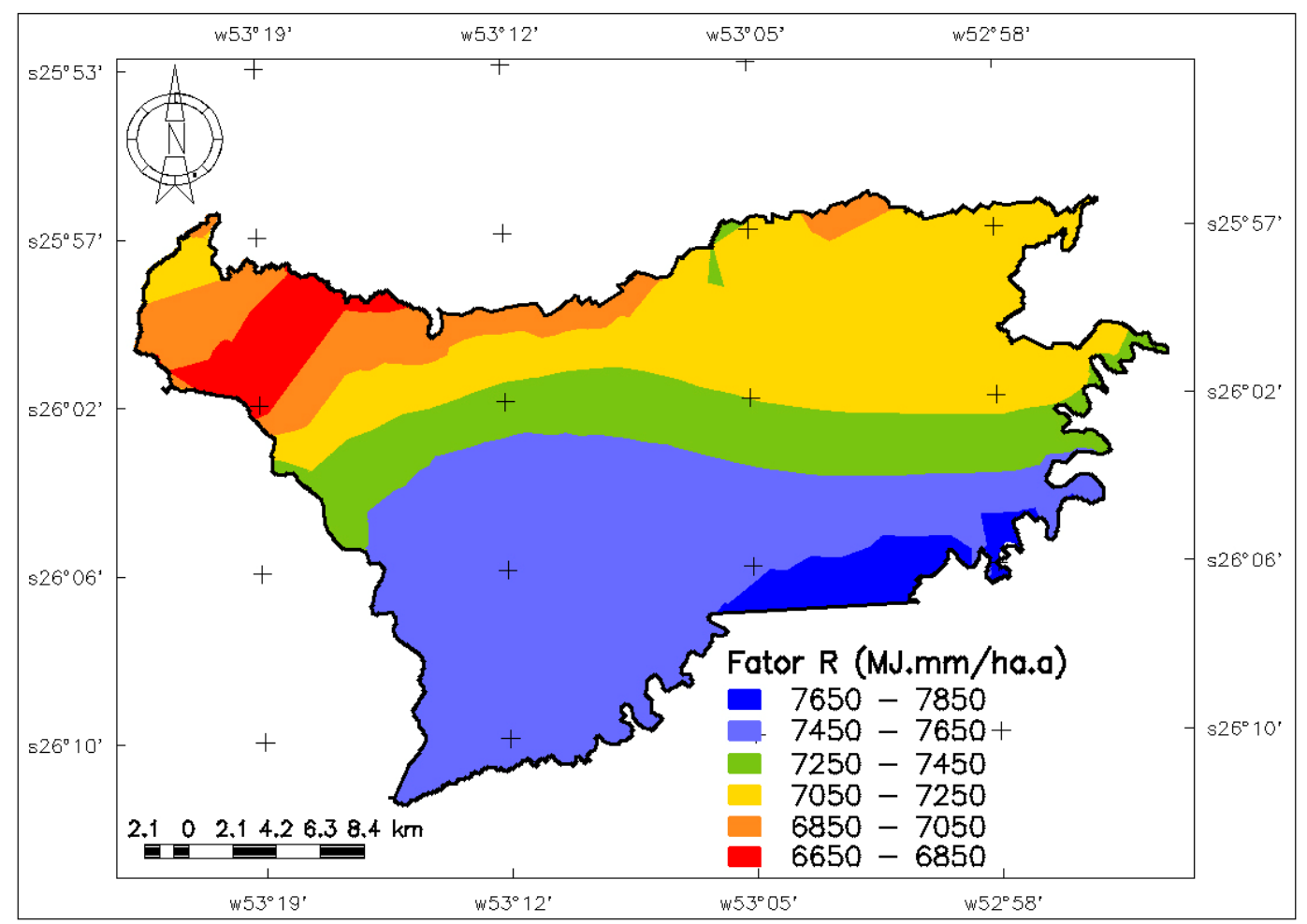

FIGURA 2. Mapa da erosividade $\left(\mathrm{MJ} \cdot \mathrm{ha}^{-1} \cdot \mathrm{mm} \cdot \mathrm{h}^{-1} \cdot \mathrm{ano}^{-1}\right)$ no município de Francisco Beltrão.

$\mathrm{Na}$ Tabela 2 são apresentados os intervalos do fator erosividade e as áreas ocupadas por cada intervalo. Em 42,04\% da área do município, com erosividade entre 7450 e $7850 \mathrm{MJ} \cdot \mathrm{ha}^{-1} \cdot \mathrm{mm} \cdot \mathrm{h}^{-1}$.ano ${ }^{-1}$, a capacidade erosiva da precipitação média anual é considerada média forte de acordo com CARVALHO (2008). A maior parte do município, 45,61\%, apresenta uma erosividade média, com valores variando entre 7050 e $7450 \mathrm{MJ} \cdot \mathrm{ha}^{-1} \cdot \mathrm{mm} \cdot \mathrm{h}^{-1} \cdot \mathrm{ano}^{-1}$.

Os valores identificados para o fator $\mathrm{R}$ foram superiores aos encontrados por ELTZ et al., (2011) no Rio Grande do Sul e por SCHICK et al., (2014) em município 
de Santa Catarina. No entanto, localiza-se dentro do intervalo de variação investigado por OLIVEIRA et al., (2013) para valores de erosividade no Brasil.

TABELA 2. Áreas classificadas do fator erosividade no município de Francisco Beltrão.

\begin{tabular}{cccc}
\hline Fator R & (MJ.ha-1.mm.h-1.ano-1) & Área (ha) & Área (\%) \\
\hline $6650-6850$ & 2874,07 & 3,93 \\
$6850-7050$ & 6159,44 & 8,41 \\
$7050-7250$ & 21517,75 & 29,39 \\
$7250-7450$ & 11877,01 & 16,22 \\
$7450-7650$ & 27993,81 & 38,24 \\
$7650-7850$ & 2780,45 & 3,80 \\
\hline Total & 73202,53 & 100,00 \\
\hline
\end{tabular}

\section{Fator Erodibilidade (K)}

De acordo com a análise granulométrica realizada nas amostras de solo coletadas e considerando o teor de argila obtido, foram observados solos com textura muito argilosa e argilosa em $60 \%$ e $40 \%$ das amostras analisadas, respectivamente. $\mathrm{O}$ agrupamento entre as partículas em solos com textura argilosa promove uma resistência maior do solo contra a atuação da água sobre ele. Assim os valores de erodibilidade para o município de Francisco Beltrão tendem a apesentar valores baixos.

$\mathrm{Na}$ Tabela 3 estão apresentados os tipos de solos existentes no município e os valores encontrados para a erodibilidade em horizonte A. Nota-se a predominância de nitossolos, em $57,25 \%$ da área do município, com o valor mais alto de erodibilidade de 0,0177 tha ${ }^{-1} \cdot h \cdot \mathrm{mm}^{-1} \cdot$ ha. $\mathrm{MJ}^{-1}$.

TABELA 3. Tipos de solos e fator erodibilidade em horizonte A para 0 município de Francisco Beltrão.

\begin{tabular}{cccc}
\hline Solos & Fator K & Área Total (ha) & Área Total (\%) \\
\hline LVdf $^{1}$ & 0,0159 & 21991,07 & 30,12 \\
LVef $^{2}$ & 0,0159 & 7965,68 & 10,91 \\
$\mathrm{NVdf}^{3}$ & 0,0177 & 16579,60 & 22,70 \\
$\mathrm{NVef}^{4}$ & 0,0177 & 25229,33 & 34,55 \\
$\mathrm{RRe}^{5}$ & 0,0171 & 690,26 & 0,95 \\
$\mathrm{RRd}^{6}$ & 0,0171 & 567,42 & 0,78 \\
\hline Total & - & 73023,36 & 100,00 \\
\hline
\end{tabular}

'Latossolo Vermelho distroférrico; ${ }^{2}$ Latossolo Vermelho eutroférrico; ${ }^{3}$ Nitossolo Vermelho distroférrico; ${ }^{4}$ Nitossolo Vermelho eutroférrico; ${ }^{5}$ Neossolo Regolítico eutrófico;; ${ }^{6}$ Neossolo Regolítico eutrófico.

Representando uma porcentagem de área de $41,03 \%$, estão presentes os latossolos, exibindo o menor valor de erodibilidade de 0,0159 t.ha ${ }^{-1} \cdot h \cdot \mathrm{mm}^{-1} \cdot$ ha.MJ ${ }^{-1}$. Com uma área pouco significativa, apenas 1,73\%, aparecem os neossolos, com valor médio de erodibilidade 0,171 t.ha ${ }^{-1} \cdot h \cdot \mathrm{mm}^{-1} \cdot$ ha. $\mathrm{MJ}^{-1}$. Utilizando o método 
proposto por DENARDIN (1990), ARRAES et al (2010) e DEMARCHI \& ZIMBACK (2014) encontraram valores maiores de erodibilidade para tipos de solos semelhantes em São Paulo, porém próximos aos encontrados neste trabalho. Observando a classificação proposta por BERTONI \& LOMBARDI NETO (2008) esses valores são considerados baixos.

A Figura 3 expõe o mapa gerado da erodibilidade em horizonte $A$ ao longo da extensão do município de Francisco Beltrão.

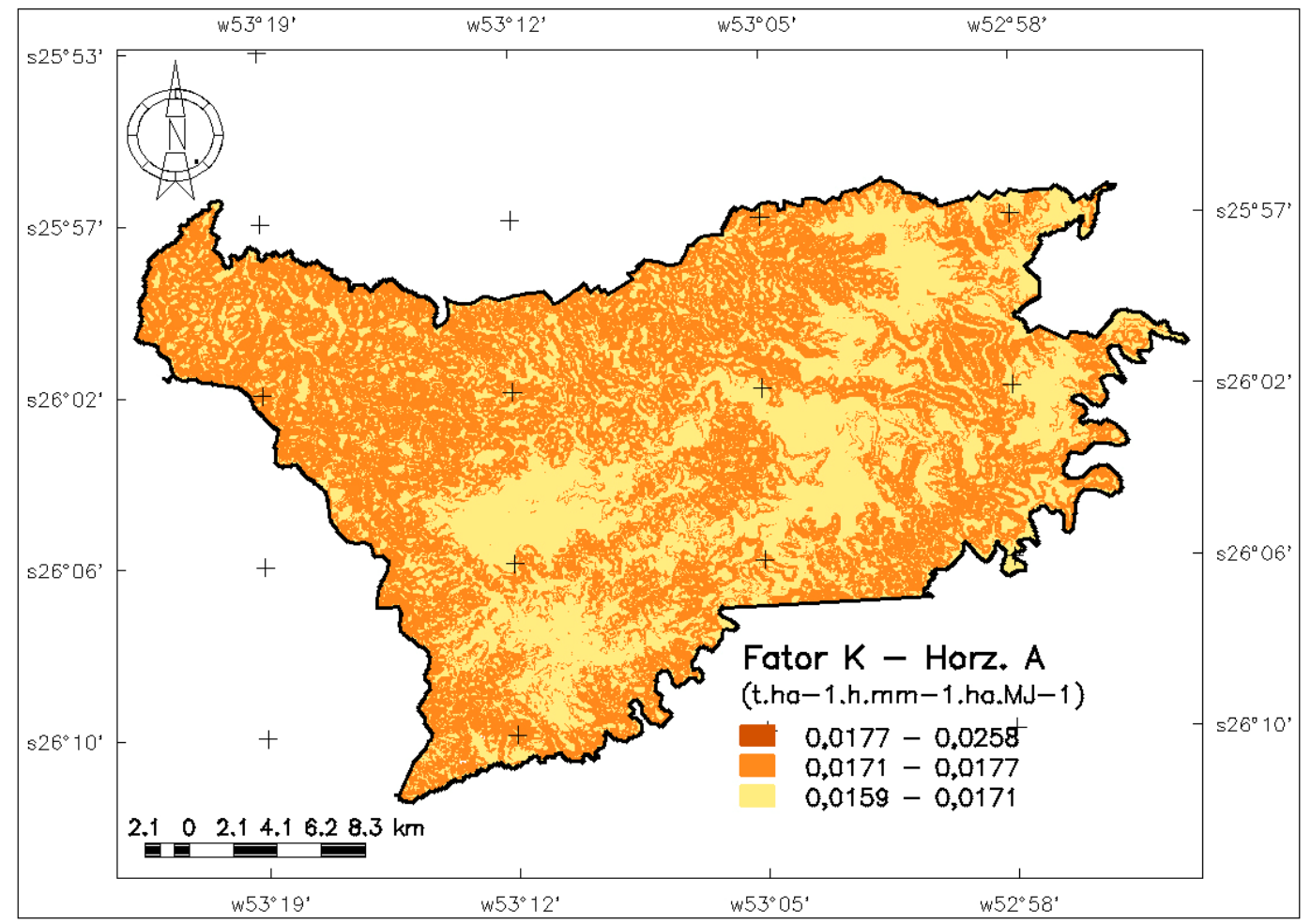

FIGURA 3. Mapa do fator erodibilidade em horizonte A no município de Francisco Beltrão.

\section{Fator Topográfico (LS)}

De acordo com a classificação da EMBRAPA (1984), no município de Francisco Beltrão há a predominância de relevo ondulado a forte-ondulado, seguido do relevo forte-ondulado a montanhoso, correspondendo a $39,14 \%$ e $29,14 \%$, respectivamente (Tabela 4). Esses valores de declividade evidenciam a influência no processo erosivo, uma vez que inclinações elevadas irão avolumar o escoamento da água na superfície. No entanto, observa-se a ocorrência de uma declividade de até $3 \%$, apresentando um relevo plano, em uma porcentagem de área de $19,48 \%$. Ainda, em $10,48 \%$ da superfície, encontra-se um relevo plano a suave-ondulado, com classe de declividade entre $3 \%$ e $8 \%$.

TABELA 4-Áreas e classificação da declividade no município de Francisco Beltrão

\begin{tabular}{cccc}
\hline Declividade & Área (ha) & Área (\%) & Classificação $^{(1)}$ \\
\hline $0-3 \%$ & 14229,55 & 19,48 & Plano \\
$3-8 \%$ & 7650,71 & 10,48 & Plano a Suave-Ondulado \\
$8-20 \%$ & 28581,18 & 39,14 & Ondulado a Forte-Ondulado \\
$20-45 \%$ & 21304,58 & 29,17 & Forte-Ondulado a Montanhoso \\
$45-75 \%$ & 1263,90 & 1,73 & Montanhoso \\
\hline Total & 73029,92 & 100,00 & - \\
\hline (1)EMBRAPA (1984). & & &
\end{tabular}


Os intervalos calculados para o fator topográfico foram divididos em 7, variando entre 0 e maiores que 20 e são demonstrados na Figura 4.

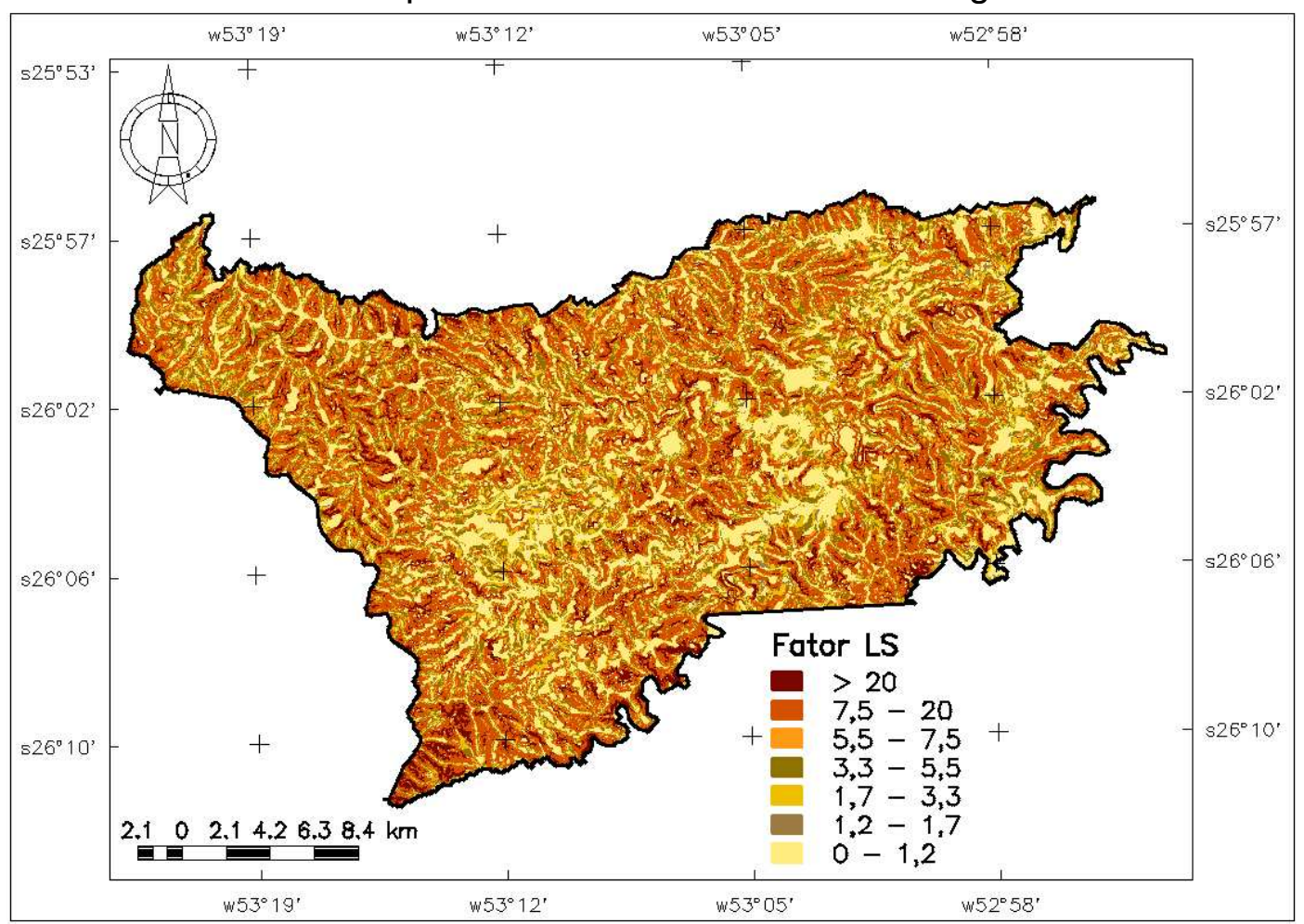

FIGURA 4. Mapa do fator topográfico no município de Francisco Beltrão.

Partindo da classificação adotada por FORNELOS \& NEVES (2007), foi verificado, na Tabela 5 , que $36,08 \%$ da área do município apresenta classes do fator topográfico entre baixo e muito baixo. Entretanto, há a ocorrência de classe forte em $39,44 \%$ do território do município, representado por valores do fator topográfico entre 7,5 e maiores que 20. Representando classes moderada e moderadamente forte, estão os valores do fator topográfico entre 3,3 e 7,5, ocupando $24,47 \%$ da área total do município.

TABELA 5. Áreas do fator topográfico (LS) no município de Francisco Beltrão.

\begin{tabular}{cccc}
\hline Fator LS & Área (há) & Área (\%) & Classificação $^{(1)}$ \\
\hline $0-1,2$ & 16441,91 & 22,51 & Muito baixo \\
$1,2-1,7$ & 2442,57 & 3,34 & Baixo \\
$1,7-3,3$ & 7468,89 & 10,23 & Baixo \\
$3,3-5,5$ & 9938,95 & 13,61 & Moderado \\
$5,5-7,5$ & 7932,73 & 10,86 & Moderadamente forte \\
$7,5-20$ & 23821,25 & 32,62 & Forte \\
$>20$ & 4983,62 & 6,82 & Forte \\
\hline Total & 73029,92 & 100 & - \\
\hline (1) Adaptado de FORNELOS \& NEVES (2007).
\end{tabular}

\section{Fator Uso e Manejo do Solo e Práticas Conservacionistas (CP)}

No levantamento do uso e ocupação do solo no município de Francisco Beltrão foram utilizadas seis diferentes classes de uso (Tabela 6). A partir dessa classificação foram determinados os valores do fator uso e manejo do solo e práticas conservacionista, e representados na Figura 5. 


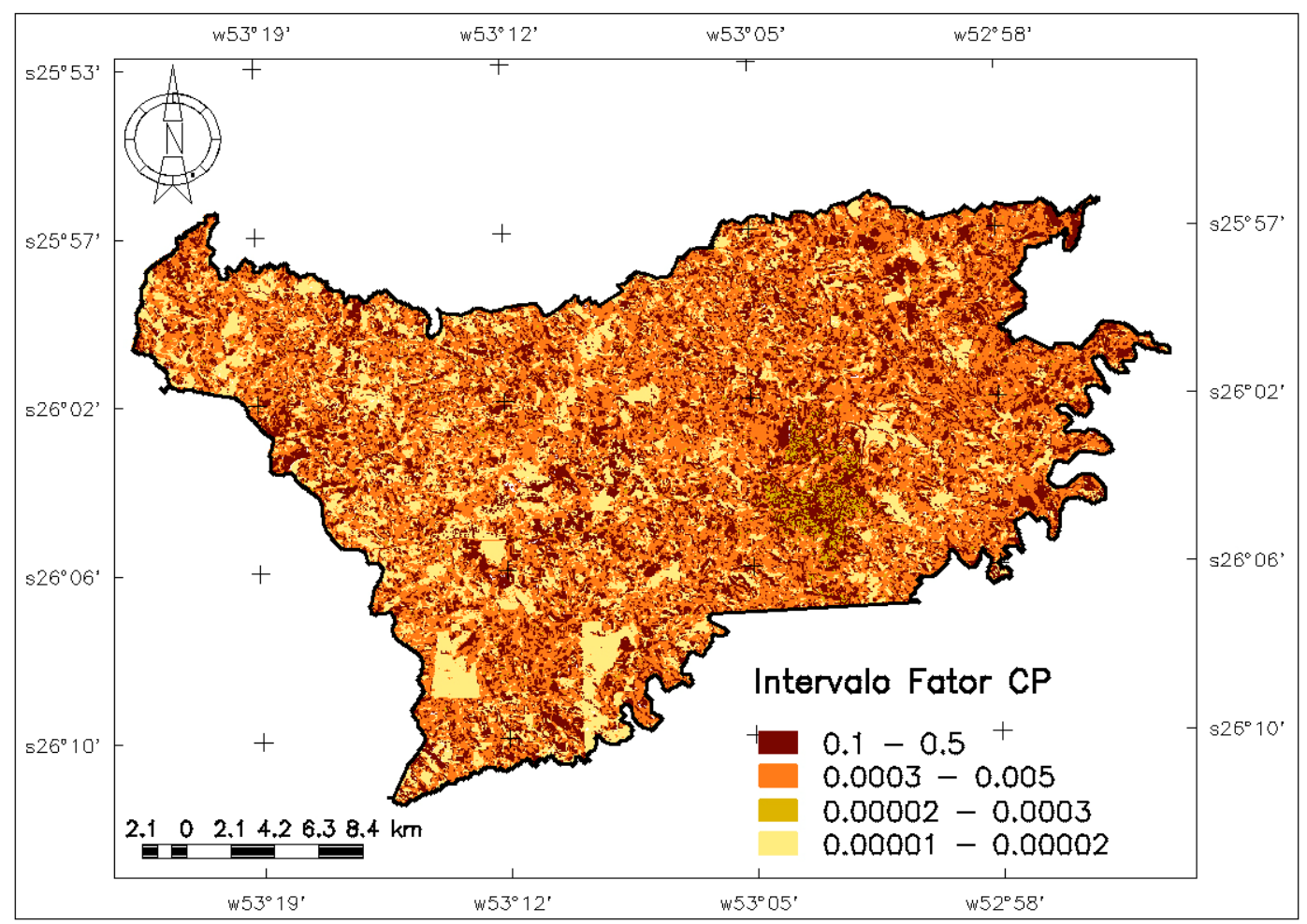

FIGURA 5. Distribuição das classes do fator CP (adimensional) ao longo do município de Francisco Beltrão.

Envolvendo uma área de $29,08 \%$ e compreendendo os maiores valores do fator $\mathrm{CP}$, entre 0,1 a 0,5 , apresentam-se as formas de uso lavoura, lavoura em pousio de inverno e solo exposto, confirmando a maior suscetibilidade do solo quando expostos à essas classes de uso, uma vez que oferecem pouca proteção ao solo.

No terrítorio do município de Francisco Beltrão, 22,32\% da área é ocupada por mata secundária, que oferece maior cobertura ao solo e evita o agravamento dos processos erosivos, logo, comprovou-se que os menores valores do fator CP se encontram nessa classe de uso do solo. As Pastagens ocupam a maior porcentagem de área no município, 46,97\%, e expõe valores moderados do fator $\mathrm{CP}$, entre 0,0003 e 0,005 e proporcionam uma proteção intermediária ao solo.

TABELA 6. Fator CP e áreas de uso do solo no município de Francisco Beltrão.

\begin{tabular}{cccc}
\hline Uso do Solo & Fator CP & Área Total (ha) & Área (\%) \\
\hline Mata Secundária & $0,00001-0,00002$ & 16295,74 & 22,32 \\
Urbanização & $0,00002-0,0003$ & 1190,39 & 1,63 \\
Pastagem & $0,0003-0,005$ & 34294,05 & 46,97 \\
Lavoura & $0,1-0,5$ & 8638,81 & 11,83 \\
Lavoura em Pousio & $0,1-0,5$ & 3380,11 & 4,63 \\
Solo Exposto & $0,1-0,5$ & 9211,55 & 12,62 \\
\hline Total & - & $\mathbf{7 3 0 1 0 , 6 3}$ & 100,00 \\
\hline
\end{tabular}

\section{Perda Anual de Solo (A)}

De acordo com a Tabela 7 e com a classificação utilizada pela FAO (1967), no município de Francisco Beltrão as perdas anuais de solo encontradas entre nenhuma ou ligeira, compreendendo perdas entre 0 e 10 t.ha $^{-1}$.ano ${ }^{-1}$, predominam ENCICLOPÉDIA BIOSFERA, Centro Científico Conhecer - Goiânia, v.13 n.23; p.1234 
em $71,70 \%$ do território municipal. Em apenas 4,9\% da área as perdas de solo se encontram entre 10 a 50 t.ha $^{-1}$.ano ${ }^{-1}$, sendo classificadas como perdas de solo moderadas. Outros 4,06\% apresentam perdas de solo altas, compreendendo um decréscimo de solo entre 50 a 100 t.ha $^{-1} \cdot$ ano $^{-1}$. Em uma porcentagem considerável da área do município, abrangendo 15,54\%, observam-se perdas de solo consideradas muito altas, com valores maiores que 100 t.ha $^{-1}$.ano ${ }^{-1}$.

TABELA 7. Áreas com perda de solo (t.ha ${ }^{-1} \cdot a^{-1} o^{-1}$ no município de Francisco Beltrão.

\begin{tabular}{cccc}
\hline $\begin{array}{c}\text { Perda de Solo } \\
\text { (t.ha-1ano-1) }\end{array}$ & Área (ha) & Área (\%) & Classificação(1) $^{(\mathbf{1})}$ \\
\hline $0-2,5$ & 33939,95 & 46,63 & Nenhuma ou ligeira \\
$2,5-5,0$ & 9238,52 & 12,69 & Nenhuma ou ligeira \\
$5,0-10$ & 9011,88 & 12,38 & Nenhuma ou ligeira \\
$10-15$ & 2774,44 & 3,81 & Moderada \\
$15-20$ & 1058,98 & 1,45 & Moderada \\
$20-50$ & 2497,98 & 3,43 & Moderada \\
$50-100$ & 2954,74 & 4,06 & Alta \\
$>100$ & 11308,46 & 15,54 & Muito alta \\
\hline Total & 72784,95 & 100 & \\
& & &
\end{tabular}

$\mathrm{Na}$ Figura 6 estão representadas as perdas médias anuais de solo para o município de Francisco Beltrão e pode-se notar uma relação com o uso e ocupação do solo do município. No geral, os menores valores de perda de solo estão diretamente ligados à forma de uso do solo mata secundária. Da mesma maneira, as áreas com solo desprotegido, são as que apresentam maiores perdas de solo no município.

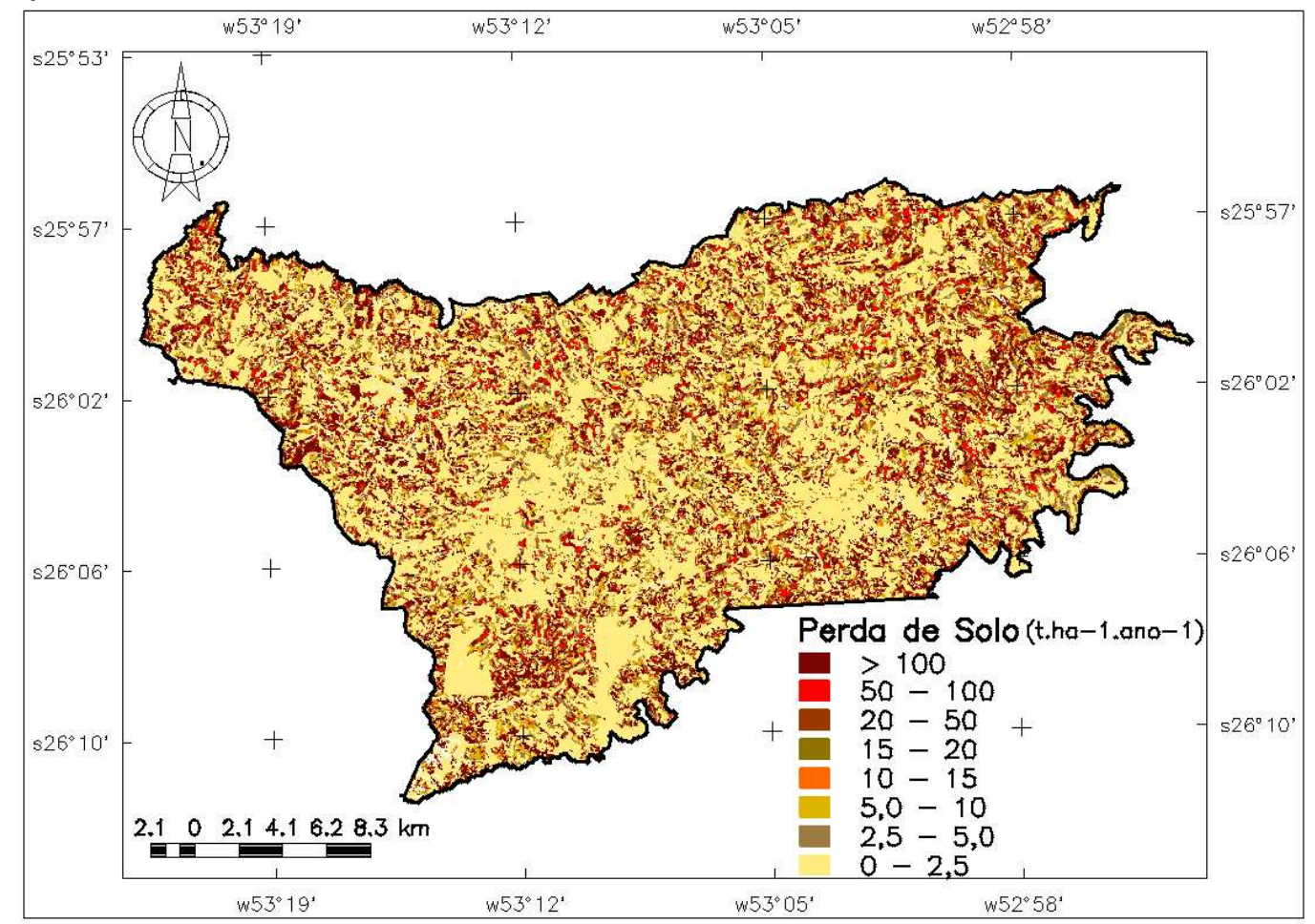

FIGURA 6. Mapa da perda média anual de solo $\left(\mathrm{t}^{\mathrm{h}} \mathrm{ha}^{-1}\right.$.ano $\left.{ }^{-1}\right)$ no município de Francisco Beltrão. 


\section{CONCLUSÕES}

O uso da linguagem LEGAL incorporada aos fatores da EUPS possibilitou observar a influência desses parâmetros na perda de solo do município de Francisco Beltrão.

A integração dos dados indicou eficiência na identificação da perda de solo por erosão hídrica e permitiu a análise das potencialidades do município, referente aos usos do solo atuais e sua influência na perda de solo.

Quando incorporada a sistemas de informação geográfica, a equação universal de perda de solo (EUPS) pode ser aplicada na estimativa da perda de solo presente em áreas maiores. A espacialização da perda de solo expressa informações importantes para o controle de práticas que intensifiquem o processo erosivo no município de Francisco Beltrão.

\section{AGRADECIMENTOS}

À UTFPR por oferecer condições e subsídios à realização do estudo juntamente com a Fundação Araucária pelo incentivo a projetos de pesquisa e desenvolvimento.

\section{REFERÊNCIAS}

ARRAES, C. L.; BUENO, C. R. P.; PISSARRA, T. C. T. Estimativa da Erodibilidade do Solo Para Fins Conservacionistas na Microbacia Córrego do Tijuco, Sp. Bioscience Journal, v. 26, n. 6, p. 849-857, 2010. Disponível em <http://www.seer.ufu.br/index.php/biosciencejournal/article/viewFile/7218/6604> ISSN 1981-3163.

BERTONI, J., \& LOMBARDI NETO, F. (2008). Conservação Do Solo. São Paulo: Ícone.

CARVALHO, N. O. Hidrossedimentologia prática. Rio de Janeiro: Interciência, 2 ed, 2008.

DEMARCHI, J. C.; ZIMBACK, C. R. L. Mapeamento, Erodibilidade e Tolerância de Perda de Solo na Sub-Bacia do Ribeirão das Perobas. Energia na Agricultura, v.29, n.2, p.102-114, 2014. Disponível em <http://dx.doi.org/10.17224/EnergAgric.2014v29n2p102-114> doi: 10.17224/EnergAgric.2014v29n2p102-114.

DENARDIN, J. E. Erodibilidade de Solo Estimada por meio de Parâmetros Físicos e Químicos. 1990. 125f. Tese (Doutorado em Agronomia) - Escola Superior De Agricultura Luiz De Queiroz, Universidade De São Paulo, Piracicaba - Sp.

DEVATHA, C. P.; DESHPANDE, V.; RENUKAPRASAD, M. S. Estimation of Soil loss Using USLE Model for Kulhan Watershed, Chattisgarh- A Case Study. Aquatic Procedia, v.4, p.1429-1436, 2015. Disponível em <http://dx.doi.org/10.1016/j.aqpro.2015.02.185> doi: 10.1016/j.aqpro.2015.02.185

ELTZ, F. L. F.; CASSOL, E. A.; PASCOTINI, P. B. Potencial erosivo e características das chuvas de Encruzilhada do Sul, RS. Revista Brasileira de Engenharia Agrícola e Ambiental, v.15, p.331-337, 2011. Disponível em 
<http://dx.doi.org/10.1590/S1415-43662011000400001>. doi: 10.1590/S141543662011000400001.

EMBRAPA - Empresa Brasileira de Pesquisa Agropecuária. Mapa de solos do Estado do Paraná: Legenda Atualizada. Rio de Janeiro: Embrapa Florestas: Embrapa Solos: IAPAR - Instituto Agronômico do Paraná, 2008. 74p.

EMBRAPA - Empresa Brasileira de Pesquisa Agropecuária. Manual De Métodos De Análise De Solos. 2 Ed. Rio De Janeiro - Rj: Centro Nacional De Pesquisa De Solos, 1997.

FAO - FOOD AND AGRICULTURE ORGANIZATION. La erosion del suelo por el água: Algunas medidas para combatirla em las tierras de cultivo. Cuadernos de fomento agropecuario 81. Roma: Organizacion de Las Naciones Unidas - FAO, n.81, 1967. 207p.

FORNELOS, L. F.; NEVES, S. M. A. S. Uso de modelos digitais de elevação (MDE) gerados a partir de imagens de radar interferométrico (SRTM) na estimativa de perdas de solo. Revista Brasileira de Cartografia, n.59/1, p.25-33, 2007. Disponível em $<$ http://www.Isie.unb.br/rbc/index.php?journal=rbc\&page=article\&op=view\&path\%5B \%5D=205\&path\%5B\%5D=206> ISSN: 1808-0936.

GANASRI, B. P. RAMESH, H. Assessment of soil erosion by RUSLE model using remote sensing and GIS - A case study of Nethravathi Basin. Geoscience Frontiers, p.1-9, 2015. Disponível em <http://dx.doi.org/10.1016/j.gsf.2015.10.007> doi: 10.1016/j.gsf.2015.10.007.

GUIMARÃES, R. Z.; LINGNAU, C.; RIZZI, N. E.; SCHEICHI, R. G.; BIANCHI, R. C. Espacialização da Perda de Solo por Erosão Laminar na Microbacia do Rio Campinas, Joinville SC. RAEGA, v.23, p.534-554, 2011. Disponível em <http://dx.doi.org/10.5380/raega.v23i0.24920> doi: 10.5380/raega.v23i0.24920.

INPE - INSTITUTO NACIONAL DE PESQUISAS ESPACIAIS. Imagens do Satélite LANDSAT - 8. Órbita 160, Ponto 129, composição colorida nas bandas 2, 3 e 4 (BRG). Data: 27.07.2013. Disponível em <http://www.dgi.inpe.br/CDSR/> Acesso em: 27.10.2013.

INPE - INSTITUTO NACIONAL DE PESQUISAS ESPACIAIS. SPRING 5.2.6 Sistema de Processamento de Informações Georeferenciadas. 2014. Disponível em: <http://www.dpi.inpe.br/spring > acesso em 07/01/2014.

MATI, B. M.; MORGAN, R. P. C.; GICHUKIC, F. N.; QUINTONB, J. N.; BREWERB, T. R.; LINIGERD, H. P. Assessment of erosion hazard with the USLE and GIS: A case study of the Upper Ewaso Ng'iro North basin of Kenya. International Journal of Applied Earth Observation and Geoinformation, v.2, n.2, p.78-86, 2000. Disponível em <http://dx.doi.org/10.1016/S0303-2434(00)85002-3> doi: 10.1016/S0303-2434(00)85002-3. 
NEVES, S. M. A. S.; MOTINHO, M. C.; NEVES, R. J.; SOARES, E. R. C. Estimativa da Perda de Solo Por Erosão Hídrica na Bacia Hidrográfica do Rio Jauru/MT. Revista Sociedade e Natureza, ano 23, n.3, p.423-434, 2011. Disponível em <http://dx.doi.org/10.1590/S1982-45132011000300005> doi: 10.1590/S198245132011000300005.

NÓBREGA, C.; COSTA, A. L. C. Estudo da Vulnerabilidade à Erosão na Alta Bacia do Rio Jacaré Pepira Utilizando Modelo Baseado na Equação Universal de Perda de Solo. HOLOS Environment, v.8, n.1, p.1-17, 2008. Disponível em <http://www.periodicos.rc.biblioteca.unesp.br/index.php/holos/article/view/2534/2232 $>$ ISSN: 1519-8634.

OLIVEIRA, P. T. S.; WENDLAND, E.; NEARING, M. A. Rainfall erosivity in Brazil: A review. Catena, v.100, p.139-147, 2013. Disponível em <http://dx.doi.org/10.1016/j.catena.2012.08.006> doi: 10.1016/j.catena.2012.08.006

SANTOS, D. B. O.; BLANCO, C. J. C. PESSOA, F. C. L. RUSLE para Determinação da Tolerância de Perda de Solo. Biota Amazônia, v.5, n.4, p.78-83, 2015. Disponível em <http://dx.doi.org/10.18561/2179-5746/biotaamazonia.v5n4p78-83> doi: 10.18561/2179-5746/biotaamazonia.v5n4p78-83.

SCHICK, J.; BERTOL, I.; COGO, N. P.; GONZÁLEZ, A. P. Erosividade das chuvas de Lages, Santa Catarina. Revista Brasileira de Ciência do Solo, v.38, n.6, p.1890-1905, 2014. Disponível em <http://dx.doi.org/10.1590/S010006832014000600024> doi: 10.1590/S0100-06832014000600024.

SUDERHSA - Superintendência De Desenvolvimento Dos Recursos Hídricos E Saneamento Ambiental. Atlas de Recursos Hídricos do Estado do Paraná. Curitiba, PR. 1998.

WISCHMEIER, W.H.; SMITH, D.D. Predicting rainfall erosion losses: a guide to conservation planning. Washington: USDA, 1978. 57p. (USDA Agricultural Handbook, 537). 